\title{
Transforming care for older people in hospital: physicians must embrace the challenge
}

D Oliver

\section{Why this matters}

The English National Health Service (NHS) is caught in a 'perfect storm' relating to older people's care in hospital. A recent series of reports repeatedly highlights a picture of poor or variable care and a once-in-a-generation opportunity to transform services, which physicians must grasp. The public dialogue in the media, ${ }^{1,2}$ public office, ${ }^{3,4}$ campaigns $^{5,6}$ and studies ${ }^{7,8}$ exploring the causes of poor care has majored on the crucial role of nursing and nurses, with doctors peripheral to the story. We must take our share of responsibility for the problems and for lasting solutions, ensuring that the care of our oldest patients consistently meets the standards that they and their families have the right to expect.

Ham, ${ }^{9}$ anticipating report of the Francis Enquiry ${ }^{10}$ into failings at Mid-Staffordshire Hospitals, said 'These failures raise fundamental questions about doctors, nurses and other frontline staff working at the hospital and why they did not act sooner or more decisively to prevent failures happening. We should not complacently assume that such examples are just 'outliers' and could never happen where we work. Many contributory factors lie outside our direct control, with wider systems, professions or agencies, but I focus here on those issues that are in the gift of doctors to solve, collectively and individually. Being unable to do everything is a poor excuse for doing much less than we should.

\section{Official NHS values on the care of our oldest patients}

The NHS Constitution ${ }^{11}$ guarantees provision of ' $a$ comprehensive service available to all, based on clinical need alone reflecting the needs and preferences of patients, carers and their families...' The 2010 Equality Act $^{12}$ bans age-based discrimination in public services such as healthcare, stating that 'age-based discrimination has no place in a fair society which values all its members'.

The NHS Operating framework for $2012-13^{13}$ prioritises the care of older people and those with dementia, stating 'some parts of the NHS are failing to provide elderly and vulnerable patients with dignified and compassionate care or to offer good standards in areas such as nutrition, continence and communication'. The

D Oliver, ${ }^{1}$ visiting professor of medicine for older people; ${ }^{2}$ consultant physician (geriatric and general internal medicine).

${ }^{1}$ School of Community and Health Sciences, City University, London.

${ }^{2}$ Royal Berkshire NHS Foundation Trust.
National Dementia Strategy emphasises the need to improve dementia care in hospitals. ${ }^{14}$ The Human Rights Act, Mental Capacity Act, Deprivation of Liberty Safeguards and vulnerable adult safeguarding policies offer a range of legal protections for older patients.

Clinical guidelines from the National Institute for Health and Clinical Excellence (NICE) exist for conditions that are common in older patients including dementia, delirium, falls, bone fragility and fractures, urinary and faecal incontinence, and poor nutrition. Numerous toolkits, strategies and guidelines are produced by colleges, specialist societies, charities and government, promoting quality care for older people.

So we have many markers on both best and unacceptable practice. How well are we really delivering against these ambitions?

\section{Quality and dignity in care for older people in hospital: evidence of failings}

The 2008 Parliamentary Enquiry ${ }^{15}$ into the Rights of Older People in Health and Social Care detailed common failings around communication, respect, discriminatory attitudes, privacy, choice and control, assistance with nutrition and hydration, continence care, pain management, physical environment on the wards, discharge from hospital and end of life care, concluding that ' while there is much excellent care ... an entire culture change is needed'. These issues mirror recent reports by the NHS Ombudsman, ${ }^{16}$ the Patients' Association, ${ }^{6}$ the Care Quality Commission (CQC) Dignity and Nutrition Inspections, ${ }^{17}$ as well as comprehensive reviews on discrimination in health services by the Centre for Policy on Aging ${ }^{18}$ and reports on the general hospital care of patients with dementia.,19 They are also the issues of greatest concern to older patients and their carers with regard to their care in hospital.,6,18,19,20 The 'entire culture change' has yet to occur and hospital doctors have given inadequate sustained attention to these patient priorities, focusing instead on aspects of care that some might find more intellectually rewarding.

A balanced approach is required rather than sensation, scandal and simplistic analyses. Constructive, effective solutions require multiple approaches and go beyond 'knee-jerk' blaming of clinical staff. While there are extreme cases of wilful neglect or abuse, many factors often conspire so that essentially caring staff deliver sub-optimal care. These include shortcomings in skills, knowledge and training, together with problems stemming from factors such as culture, leadership (at all levels), system pressures, resource limitations, rules, priorities and incentives, staffing 
(numbers, support and morale) and the physical environment on wards. ${ }^{7,21,22,23}$

Satisfaction with the NHS in general, and with services individually received, is generally high in older people ${ }^{24}$ and there is much excellent practice to celebrate. Nonetheless, a growing weight of evidence suggests that we could do better. One in five hospitals inspected by the CQC in 2011 exhibited 'basic failings' on dignity and nutrition. ${ }^{17}$ Eighteen percent of the 9,000 complaints received by the NHS Ombudsman in 2010-11 concerned the care of vulnerable older people. ${ }^{16}$ Of patients over 65 admitted to hospital in 2009-10, only 5\% rated their care as poor or fair on the inpatient survey ${ }^{24}$ whereas $83 \%$ rated the care they received as good or excellent. This 5\% still equates to around 250,000 older people who were dissatisfied. Many feel they have justified complaints but don't make them formally, partly because they find the system off-putting. And older patients who are frail, ill or disabled are less likely to complete surveys or make complaints, and might also be inclined to generational gratitude or deference to the NHS. Complaints often originate instead from family caregivers. They should be investigated quickly, carefully and fairly to ensure that clinical staff don't suffer unjust blame without redress, and that complainants' concerns are answered openly and promptly. We should use complaints and feedback constructively as valuable 'capital' that can be used to design services around the needs of patients and carers in partnership with them, and to inform governance and training. The alternative, adopting reflexive defensiveness, might lead to a failure to address the questions or concerns of complainants and compound their distress.

Further evidence of gaps in fundamental assessments and interventions for older patients is provided by a series of major national audits on continence, ${ }^{25}$ falls ${ }^{26}$ and fractures, ${ }^{27}$ hip fracture, ${ }^{28}$ nutrition, ${ }^{29}$ perioperative care ${ }^{30}$ and dementia care in hospitals, ${ }^{19}$ and by surveys on the experience of end of life care ${ }^{31}$ or hospital discharge. ${ }^{32}$ Exploratory studies on the causes of undignified care of older people in hospital, ${ }^{7,8}$ and on the bewildering experience they have when dealing with multiple services and professions, ${ }^{32}$ have provided rich descriptive information.

Our 'perfect storm' could blow more fiercely fuelled by momentum provided by the NHS Confederation and Age UK Commission on Dignity in Care for Older People, ${ }^{33}$ by the new National Nursing and Care Quality Forum ${ }^{3}$ and by the Robert Francis report. Francis has already indicated areas for recommendations, ${ }^{10}$ including: the recruitment, training, regulation and supervision of clinical staff, the fitness-to-practice functions of professional bodies and a greater focus on safety and quality standards. These will have implications for us as individual clinicians and for bodies such as the RCP.

\section{A shift from describing the problem to delivering lasting solutions}

We have described repeatedly older people's concerns and priorities, evidence for best practice and examples of services that deliver it, failings in care and underlying systemic or cultural reasons for those failings. To continue merely describing the problems risks a kind of 'Groundhog Day' or 'death by awareness'. The King's Fund ${ }^{34}$ recently listed 21 high-profile UK reports and guidelines published between 1997 and 2010, all emphasising dignified essential care for older people and those with dementia. Such reports raise awareness but won't transform care unless the recommendations are systematically implemented. We must move from 'awareness' to intention to concerted action that goes beyond cosmetic 'box-ticking' and focuses on the delivery of lasting change, not simply signed-off by us as clinicians but as experienced by older patients and their carers.

Peter Aldous MP in a 2011 Westminster Hall Debate on the NHS Care of Older People ${ }^{4}$ said of the CQC Dignity and Nutrition Inspections 'There is a sense of déjà vu here, it's as if each new revelation creates a sense of outrage, then nothing happens. We have an obligation to ensure that this time it is different'.

\section{Why we as doctors must take ownership of the problem}

If this time things really are 'going to be different', then physicians must engage. We continue to care for patients, even when in senior leadership roles in hospitals, colleges, professional societies or government, bringing clinical perspective and credibility. We have influence from 'ward to board' within our own hospitals. Our personal practice, our supervision of trainees and our interactions with patients, their families and clinical colleagues all influence care quality and patient experience. The RCP has acknowledged this in recent papers on medical professionalism and leadership and in its submission to the Dignity Commission.'

Ham reinforced this in his commentary on the future NHS: ${ }^{9}$ 'the opportunity for the medical profession is to demonstrate a degree of collective leadership that in the past has been difficult to mobilise ... show the public and government that they are prepared to take a lead on safety and quality.'

\section{How we as doctors should step up to the challenge}

So how can we as physicians respond to Ham's 'call to action' to ensure that high-quality, safe, dignified and person-centred care for older people in our hospitals becomes the norm?

First, our training, priorities and attitudes need to catch up with the impact of population ageing on the nature of modern medical practice. Hospitals and medical specialities emerged in an era when many people died in childhood or midlife of single diseases. In 2012, the main activity of general hospitals is the care of (generally older) people with (multiple) long-term conditions. These are often accompanied by frailty, social vulnerability, dementia, functional or sensory impairment, and compounded by acute illness. Older patients often present acutely with syndromes such as falls, immobility, delirium or non-specific 'failure to thrive'. The care of such patients has not featured highly in traditional medical textbooks or medical training, 
which has centred on organ- or disease-specific approaches. But outside obstetrics or paediatrics, the care of older people who are vulnerable or have complex needs is every doctor's job, increasingly so as our population ages, with the 'oldest old' the fastest-growing group of patients. We need to embrace this new reality and ensure that their care is 'in our DNA' from medical school onwards. Value is added by geriatricians and others trained in the care of older people with complex needs and there is a case for expanding our numbers, but we will never have the capacity to care for all frail older people.

To quote Rockwood 'If we design services for people with one thing wrong at once, but people with many things wrong turn up, the fault lies not with the system but with the service, yet too often these patients are termed inappropriate and labelled as a problem.'35

Stephen Dorrell MP, the Chair of the Parliamentary Health Select Committee, echoed this, saying 'Some of the greatest problems in care are because traditional institutions and structures are being used to deliver care to a quite different type of patient.... Systems designed to treat occasional episodes of care for normally healthy people are being used to deliver care for people who have complex and long term conditions. The result is often that they are passed from silo to silo. ${ }^{36}$

This new reality requires a shift towards a bio-psycho-social model and towards holistic multidisciplinary care, rehabilitation and discharge planning. Close links with community services and involvement of carers should be core to our job and not a distracting irrelevance to the parts of care (diagnosis and therapeutic intervention) seen traditionally by many doctors as our main role..$^{37,38}$ We must re-balance education and training to move away from an excessive prioritisation of curative, hightech medicine as our population ages, ensuring that doctors have the skills needed to care for the majority of patients who come through the door. Appraisal, performance-management and job-planning should reinforce the right behaviours. Medical royal colleges, specialist medical societies and clinical leaders are central to delivering this paradigm shift.

At present, conditions that are associated with ageing receive less priority in training and systematically less good clinical care than common conditions of midlife. ${ }^{14,18,39}$ Furthermore, conditions that are common across age groups receive less good clinical care in older than in younger adults. Age, life expectancy and co-morbidity are legitimately relevant to many clinical decisions; but systematic differences in clinical approach are often arbitrary and might reflect instead the sometimes ageist priorities or attitudes of doctors or stereotypical assumptions about older peoples' quality of life or ability to benefit. ${ }^{12,18,37}$

Second, on the wards, doctors need to exhibit the right behaviours and act as role models to other staff. This means: 1) avoiding pejorative labels such as 'social work medicine', 'bed blocker', 'old crock' or worse; $18,37,38$ 2) 'seeing the person in the bed ${ }^{5,6,7,8,16}$ as an individual with needs, preferences, a personal story and social connections and not 'the stroke in bed 17' (sic); 3) giving older people the same information, respect, choice, and control over decisions affecting their lives (even if risky) as working-age adults; and 4) purposively involving family carers as partners in care and keeping them informed. Extreme age, disability or cognitive impairment do not legitimise a failure to respect older patients' humanity or to exercise a duty of care. Such behaviours would not be tolerated in those caring for vulnerable child patients, so why would they be acceptable for those working with vulnerable adults?

Third, we need to correct poor practice when we see it and to set a personal example by our own behaviour. We should not stand by when we see an older person lying in a wet bed, halfclothed or constantly calling out unanswered for assistance or reassurance. We should not pretend we haven't noticed patients' relatives who are obviously concerned and desperate for information or brush them off when they approach. We should challenge colleagues whose behaviour towards older patients is ageist, unprofessional or breaches basic rights. A small effort can make a major difference and often prevent concerns escalating into complaints and beyond.

In the face of the hospital machine, doctors might feel powerless to alter 'basic' care. This is an abdication of responsibility. In applied medical ethics, a key principle is that of 'scope. ${ }^{40}$ We cannot be morally responsible for delivering change over which we have no direct control, but we do have a responsibility to raise problems that compromise the care of our patients through the official channels, and if this fails, by 'whistle-blowing. For instance, if the there are inadequacies in the numbers of nursing staff or in their skills that put safe and dignified care for our patients at risk, we have a moral responsibility to raise this issue and to be 'challenging' rather than to assume that such concerns 'down to management' or 'someone else's responsibility'. The General Medical Council and the RCP are clear about this aspect of professionalism. ${ }^{41,42,43}$ Doctors have responsibility for the overall care of their patients and not merely the care that they deliver directly.

Fourth, while older people should never be denied assessment and treatment in hospital when needed, and hospital is sometimes precisely the right place for their needs to be met, we should collaborate fully with primary, mental health and social care colleagues to re-design pathways that can ensure that patients of all ages are only in acute hospital beds when this is really required. There is considerable variation ${ }^{44,45}$ among localities in rates of emergency admission, bed utilisation, emergency readmission and delayed discharge for older people. There is also growing interest in improving the management of people with long-term conditions, in anticipatory care and early intervention to prevent admission, and in providing the support necessary to allow older people to leave hospital earlier and with better community follow up. ${ }^{46,47}$ These are crucial challenges in delivering efficiencies in the NHS and in providing more integrated care. Full engagement does sometimes entail thinking outside our own organisational 'silos', ceding some control or resource to other organisations or changing our job plans uncomfortable territory for some hospital-based specialists.

Finally, we need to reject the bogus distinction between the medical-diagnostic model and essential nursing care. People with functional impairment, immobility, falls, confusion or a general 
failure to thrive at home are not 'atypical or 'non-specific', 37 they are entirely typical of the frail older people who are a main patient group in hospitals. Their conditions can often be reversed with appropriate diagnosis and treatment. Instead, they are often labelled as 'acopia' or 'social admissions' ${ }^{37}$ and later, while still having potential to improve, 'medically discharged' or written off prematurely as 'for nursing home'. Such lazy therapeutic nihilism betrays our professionalism. Hospital-based comprehensive geriatric assessment ${ }^{48,49}$ delivers benefits to patients that exceed those of many more 'high tech' interventions, including reduced mortality and increased functional independence. Performing CGA well on admission and being proactive during a patient's stay can help prevent older patients from becoming immobile, incontinent, confused or dependent, help expedite their discharge and, in turn, reduce their chance of suffering the complications often associated with complaints about undignified care..$^{50,51}$

Incontinence is not just about responding to call bells and cleaning up patients. They need a diagnosis and treatment plans, which we often fail to deliver. Poor nutritional care is not merely about caring nurses helping older people to eat. It requires skilled assessment, investigation of underlying causes and medical engagement. Many falls (which make up 35\% of all safety incidents in hospitals) could be prevented by adequate medical assessment and intervention. Delirium can potentially be prevented or its duration or severity limited by the application of diagnostic and therapeutic skills, as can distressing symptoms related to dementia. It is doctors who over-prescribe antipsychotics to older patients and fail sufficiently to address underlying causes of behavioural and psychological disturbance. ${ }^{19,50}$ Good end-of-life care requires doctors to exercise skill and knowledge in recognising the dying, to have the 'difficult conversation' and to provide adequate symptom control.

As doctors, we are not consistently doing all or any of these things well enough as the RCP has acknowledged in its own evidence to the Dignity Commission. ${ }^{52}$ It's time to up our game or risk yet more cycles of scandal, incriminatory reports, worthy statements of intention and no meaningful change. Our ageing population has changed the very nature of healthcare for good and we need to change with it.

\section{Conflict of interest}

I declare that I have no conflict of interest and the views expressed are my own and not those of any organisation.

\section{References}

1 Anon. Dignity for the elderly campaign. London: The Daily Mail; 20 September 2010. http://www.dailymail.co.uk/news/article-1313495/ Daily-Mail-honoured-Dignity-Elderly-campaign.html.

2 Odone C. Horrific neglect of the elderly in hospitals. Now the fightback begins. London: TheTelegraph. 9 November 2011. http://blogs.telegraph.co.uk/news/cristinaodone/100116410/horrific-neglect-of-theelderly-in-hospitals-now-the-fightback-begins/.

3 Nursing Standard on line. PM orders regular ward rounds, nurse leadership and reduced bureaucracy. London: Nursing Standard, 2012. http://www.nursingtimes.net/whats-new-in-nursing/acute-care/ exclusive-cameron-to-announce-nursing-forum-to-investigate-carestandards/5039851.article.

4 Hansard. Westminster Hall Debate. The NHS care of older people. London: Hansard, 2011. http://www.publications.parliament.uk/pa/ $\mathrm{cm} 201011 / \mathrm{cmhansrd} / \mathrm{cm} 111027 /$ halltext/111027h0001.htm.

5 Dignified Revolution. Ensuring that older people are treated with dignity and respect. London: Dignified Revolution, ongoing. http://dignifiedrevolution.org.uk.

6 Nursing Standard (in conjunction with the Patients' Association). C.A.R.E. campaign. London: Nursing Standard, 2011. http://nursingstandard.rcnpublishing.co.uk/campaigns/care-campaign.

7 Alzheimer's Society. Counting the cost: caring for people with dementia on hospital wards. London: Alzheimer's Society, 2009. http://alzheimers.org.uk/site/scripts/download_info.php?fileID=787.

8 Tadd W, Hillman A, Calnan S et al. Dignity in practice: an exploration of the care of older adults in acute NHS trusts. London: National Institute for Health Research, 2011. http://www.sdo.nihr.ac.uk/files/ project/SDO_FR_08-1819-218_V01.pdf.

9 Ham C. The NHS in 2012. BMJ 2011;343:d8259.

10 Francis R. The Mid-Staffordshire NHS Foundation Trust Public Enquiry 2011. www.midstaffspublicinquiry.com/news/2011/12/transcriptthursday-1-december-2011.

11 Department of Health. The NHS constitution. London: Department of Health, 2010. http://www.dh.gov.uk/prod_consum_dh/groups/dh_ digitalassets/@dh/@en/@ps/documents/digitalasset/dh_113645.pdf.

12 Carruthers I, Ormondroyd J. Achieving age equality in health and social care. Report to the secretary of state for health. London: Department of Health, 2009. http://www.dh.gov.uk/prod_consum_dh/groups/dh_ digitalassets/documents/digitalasset/dh_107398.pdf.

13 Department of Health. The operating framework for the NHS in England 2012-13. London: Department of Health, 2011. http://www. dh.gov.uk/en/Publicationsandstatistics/Publications/ PublicationsPolicyAndGuidance/DH_131360.

14 Department of Health. Living well with dementia: a national dementia strategy for England. London: Department of Health, 2009. http://www. dh.gov.uk/en/Publicationsandstatistics/Publications/ PublicationsPolicyAndGuidance/DH_094058.

15 Hansard. Report of the all parliamentary enquiry into the human rights of older people in health and social care. London: Hansard, 2008.

16 Parliamentary and Health Service Ombudsman. Care and compassion. Report of the ombudsman on ten investigations into NHS care of older people. London: Office of Parliamentary and Health Service Ombudsman, 2011. http://www.ombudsman.org.uk/_data/assets/ pdf_file/0016/7216/Care-and-Compassion-PHSO-0114web.pdf.

17 Care Quality Commission. Dignity and nutrition inspection report. London: CQC, 2011. http://www.cqc.org.uk/sites/default/files/media/ documents/20111007_dignity_and_nutrition_inspection_report.pdf.

18 Centre for Policy on Ageing. Ageism and age discrimination in health and social care in the United Kingdom. London: CPA, 2009. http://www. cpa.org.uk/agediscrimination/age_discrimination.html.

19 Royal College of Psychiatrists. National audit of dementia care in general hospitals. London: RC Psych, 2011. http://www.rcpsych.ac.uk/pdf/ The\%20Interim\%20Report.pdf.

20 Calnan M, Woolhead G, Dieppe P, Tadd W. Views on dignity in providing healthcare for older people. Nursing Times 2005;101(33): 38-41.

21 Firth-Cozens J, Cornwell J. The point of care. Enabling compassionate care in acute hospital settings. London: Kings Fund, 2009. www.kingsfund.org.uk/document.rm?id=8295.

22 City University London. Everybody matters. Sustaining dignity in care. London: City University, 2010. http://www.staff.city.ac.uk/ jacky/dignity/index.htm.

23 Royal College of Nursing. Dementia project. Improving care for people with dementia in hospital. London: RCN, 2011 (ongoing). http://www.rcn.org.uk/development/practice/dementia/rcn_demetia_ project. 
24 Care Quality Commission. Inpatient survey 2010. London: CQC, 2010. http://www.cqc.org.uk/public/reports-surveys-and-reviews/surveys/ inpatient-survey-2010.

25 Royal College of Physicians. National audit of continence care. London: RCP, 2010. http://www.rcplondon.ac.uk/resources/national-audit-continence-care.

26 Royal College of Physicians. Falling standards, broken promises. Report of the fourth national audit on falls and bone health services. London: RCP, 2011. http://www.rcplondon.ac.uk/sites/default/files/national_report.pdf.

27 HQIP. National Hip Fracture Database. Annual Report 2011. London: NHFD, 2011. http://www.nhfd.co.uk/003/hipfractureR.nsf/ NHFDNationalReport2011_Final.pdf.

28 National Confidential Enquiry into Patient Outcomes and Deaths. An age old problem. A review of the care received by elderly patients undergoing surgery. London: NCEPOD, 2010. http://www.ncepod.org. uk/2010report3/downloads/EESE_fullReport.pdf.

29 Age UK. Malnutrition in hospital: still hungry to be heard. London: Age UK, 2011. http://www.ageuk.org.uk/get-involved/campaign/malnutrition-in-hospital-hungry-to-be-heard/.

30 Department of Health. VOICES: re-design and testing to inform an national end of life care strategy. London: Department of Health, 2011. http://www.dh.gov.uk/en/Publicationsandstatistics/Publications/ PublicationsPolicyAndGuidance/DH_128787.

31 Anon. Too many problems when patients leave hospital. London: Which? Magazine 2010. http://conversation.which.co.uk/consumerrights/too-many-problems-when-patients-leave-hospital/.

32 Glasby J, Littlechild R, Ellins J et al. Understanding and improving transitions of older people. A user and carer centred approach. London: Service Delivery and Organisation programme, 2011. http://www.sdo. nihr.ac.uk/files/project/SDO_PRO_08-1809-228_V10.pdf.

33 NHS Confederation, Age UK and Local Government Group. Improving dignity in care for older people in hospital. London: NHS Confederation, 2011 (ongoing). http://www.nhsconfed.org/Events/Pages/Improvingdignity-in-care-for-older-people.aspx.

34 Kings Fund. The care of older People. Sir Roger Bannister Summit at Leeds Castle, November 2011. London: Kings Fund, 2011. http://www. kingsfund.org.uk/events/hidden_events/sir_roger_bannister.html.

35 Rockwood K. What would make a definition of frailty successful? Age Ageing 2006;34:33-4.

36 Dorrell S, Milburn A, Kerr D, Moyer B. Passing judgement on Lansley's vision. Health Service J 2011;121:14-7.

37 Oliver D. 'Acopia' and 'social admission' are not diagnoses. Why older people deserve better. J Royal Soc Med 2008;101:168-74.

38 Gawande A. The way we age now. New York: The New Yorker, 30 April 2007. http://www.newyorker.com/reporting/2007/04/30/070430fa_ fact_gawande.

39 Steel N. Self-reported quality of care consistent with 32 indicators. National population survey of adults aged 50 or more in England. BMJ 2008;337:a957.
40 Gillon R. Medical ethics: four core principles plus attention to scope. BMJ 1994;309:184-8.

41 Royal College of Physicians. Medical professionalism and leadership. London: RCP, 2011. http://www.rcplondon.ac.uk/policy/physiciandevelopment/medical-professionalism-and-leadership.

42 General Medical Council. Raising concerns and acting on patient safety. London: GMC, 2012.

43 General Medical Council. Leadership and management for doctors. London: GMC, 2012.

44 Department of Health, Right Care Team. NHS Atlas of Variation 2011, Version 2.0. London: Department of Health, 2011. http://www.rightcare.nhs.uk/index.php/atlas/atlas-of-variation-2011/.

45 Audit Commission. Joining up health and social care. Improving value for money at the health and social care interface. London: Audit Commission, 2011. http://www.audit-commission.gov.uk/sitecollectiondocuments/downloads/201111hscinterfaceEmbargo.pdf.

46 The Kings Fund. The management of long-term conditions. London: Kings Fund, 2010. http://www.kingsfund.org.uk/current_projects/gp inquiry/dimensions_of_care/the_management_of_1.html.

47 The Kings Fund; Nuffield Trust. Integrated care for patients and populations. Improving outcomes by working together. London: Kings Fund, 2011._www.kingsfund.org.uk/document.rm?id=9405.

48 Ellis G, Whitehead M, Robinson D, O’Neill D, Langhorne P. Comprehensive geriatric assessment for older people admitted to hospital. A meta-analysis of randomised controlled trials. BMJ 2011;343:d6553.

49 Harari D, Martin F, Buttery A, O’Neill S, Hopper A. The Older People's Assessment and Liaison Team (OPAL): evaluation of comprehensive geriatric assessment in acute medical inpatients. Age Ageing 2007;36:370-5

50 ECIST. Priorities in acute hospitals. London: IMAS, 2011. http://www. nhsimas.nhs.uk/fileadmin/Files/IST/ECIST_-_Priorities_within_ Acute_Hospitals_2011.pdf.

51 Banerjee S. The use of antipsychotics in people with dementia. Time for action. London: Department of Health, 2009. http:/www.dh.gov.uk/ prod_consum_dh/groups/dh_digitalassets/documents/digitalasset/ dh_108302.pdf.

52 Royal College of Physicians. Evidence to NHS Confederation and Age UK commission in improving dignity in care for older people. London: RCP, 2011. http://www.rcplondon.ac.uk/sites/default/files/rcp_ reponse_to_dignity_in_care_consultation_september_2011.pdf.

Address for correspondence: Prof. D Oliver, School of Community and Health Sciences, City University,

London E1 2EA.

Email: David.Oliver.1@city.ac.uk 